\title{
MACHINING OF POLYMERIC COMPOSITES BY MEANS OF ABRASIVE WATER-JET TECHNOLOGY
}

\author{
Miroslav Muller ${ }^{1}$, Roberto D’Amato ${ }^{2}$, Anna Rudawska ${ }^{3}$ \\ ${ }^{1}$ Czech University of Life Sciences Prague; ${ }^{2}$ Universidad Politecnica de Madrid, Spain; \\ ${ }^{3}$ Politechnika Lubelska, Poland \\ muller@tf.czu.cz,r.damato@upm.es, a.rudawska@pollub.pl
}

\begin{abstract}
The water-jet cutting technology represents an effective cutting tool for diverse materials. It is prospective in the area of composite materials, which represent a combination of a hard and a soft component. An advantage of the water-jet cutting is that the cut (the material) is not heat affected, namely at the polymeric materials. The abrasive water-jet with a dash of pabrasivum (a garnet MESH 80) was used for the research. The research was performed on the device AWJ CT 0806. The aim of the research was to evaluate the cutting area and delamination of the matrix and the reinforcement (a filler). The research based on the SEM analysis proved that the AWJ technology was a prospective method for cutting polymeric composite materials.
\end{abstract}

Keywords: cutting, delamination, epoxy resin, fibres, particle, scanning electron microscopy.

\section{Introduction}

Dividing of a material is a common attribute of production companies. Classically applied methods of machining are not always technically and economically the most suitable for machining of new materials [1]. Classic technologies use cutting tools above all, on the other hand, unconventional (modern) technologies use flexible cutting tools such as ultrasound, plasma, laser-jet, liquid-jet etc. [25]. Various mechanical and physical principles depending on the single machining method are used in the unconventional machining method.

The technology of the abrasive water-jet can be ranked among modern and effective machining methods of wide spectrum of materials [6]. Creating of so called "cold cut" belongs to the main advantages. It does not come to heat affecting of machined materials, to evaporation and degradation of the material. The temperature is a problematic factor mainly at machining of polymers and polymeric composites. The liquid-jet is the working tool for machining. It is completed with an ingredient of abrasive substances at the abrasive water-jet (AWJ) technology. The AWJ technology consists in a principle of generating high water pressure going through a nozzle of a small diameter so the water gains very high kinetic energy similarly as at the water-jet $[1 ; 6 ; 7]$. Abrasive particles several fold increasing its effect are added into the high-speed water stream [7]. AWJ cutting, due to its various distinct advantages over the other cutting technologies such as no thermal distortion, high machining versatility, high flexibility and small cutting forces, is being increasingly used in various industries [7]. Specific advantages of AWJ to machine difficult-to-cut materials without inducing thermal stresses have complemented this technique for machining composites [7;8]. AWJ was used at the research, i.e. abrasivum was added into the water-jet.

Manufacturers, designers and engineers recognise the ability of composite materials to produce high-quality, durable, cost-effective products [9]. Composite materials are found in many of the products used in our day-to-day lives [9]. Composites are broadly known as reinforced plastics [1013]. Specifically, composites are reinforcing fibres in a polymeric matrix. Most commonly, the reinforcing fibre is fibreglass, although high strength fibres such as aramid and carbon are used in advanced applications [9]. A distinct advantage of composites, over other materials, is the ability to use many combinations of resins and reinforcements, and therefore custom tailor the mechanical and physical properties of a structure [9]. The composite materials are widely used in the technical practice $[10 ; 14]$. The polymeric particle composites find their application in a form of so called liquid metals [14]. Not only their adhesion at the production but also at another processing, such as, e.g., methods of material dividing into required dimensions, is important at these materials.

The composites are of fibres, of particles, based on natural and synthetic fillers [14-16]. The AWJ technology is suitable for machining composite materials. This method has its advantages as well as disadvantages at machining of the composite materials. A serious damage of the material surface as well as its inner structure can occur at an encounter of the high-speed liquid with the abrasivum with the surface of the workpiece [8; 9]. Delamination is a major component defect when machining 
composites or layered materials [8;9]. It is found that crack tips are generated by a shock wave impact of the water-jet in the initial cutting stage, while delamination is a result of water penetration into the crack tips that promotes water-wedging and abrasive embedment [8; 9]. Delamination often occurs due to the high velocity impact of the jet, in particular when cutting features such as holes or slots [79; 17].

Delamination is an important factor, which can change the mechanical behaviour of composite systems during their technological processing, which may be, e.g., the water-jet cutting. Delamination can be characterized as a mode of a failure for the composite materials and can be evaluated by the scanning electron microscopy (SEM). The aim of this paper is to describe a cutting area and the process of delamination leading to weakening of a mutual phase interaction using the optical analysis.

\section{Materials and methods}

The research on the cutting area and delamination of the filler /the reinforcement at composite materials was evaluated by means of the SEM (scanning electron microscopy) analysis. The measurement was performed on the scanning electron microscope TESCAN MIRA 3 GMX. SE detector and BSE detector were used for the measurement, the accelerating voltage was $5 \mathrm{kV}$ and the working distance was ca. $15 \mathrm{~mm}$. EDX (Energy-dispersive X-ray) analysis on TESCAN MIRA 3 GMX was performed at the chosen samples. The detector Oxford X-Max 7 was used for the measurement. A point analysis was performed at the sample. The EDX method detects X-rays and it is used for quick analysis of the chemical composition of the samples. The finding of single elements and their amount is the result of the EDX analysis (in mass percentage portion). The tested composite materials were cast into a board of dimensions $210 \times 290 \mathrm{~mm}$. The test samples for the static tensile test were cut from this board by means of the AWJ method (Fig. 1 C). The test sample cut was analysed by SEM.

The tested composite materials were made from microparticles of glass-bead B159 with the concentration 40 vol. \%, corundum microparticles F80 with the concentration 40 vol. \%, short fibres of false banana Ensete Ventricosum with the concentration 5 vol. \% and glass fabric of the weight $110 \mathrm{~g} \cdot \mathrm{m}^{-2}$. A structural epoxy matrix based on reactoplastics was the matrix. The polymeric particle and short-fibre composites were made by casting into moulds from Lukopren. The polymeric fibre composite based on glass fabric was made by means of vacuum infusion. Former pieces of knowledge were used at the production of the composite materials owing to reaching optimum mechanical properties, namely the tensile strength, wear resistance etc.

The water-jet with a dash of abrasivum (a garnet MESH 80) was used for the research. The research was performed on the device AWJ CT 0806 (Fig. 1 A). The speed of the cut was $250 \mathrm{~mm} \cdot \mathrm{min}^{-1}$ (Fig. $1 \mathrm{~B}$ ). The diameter of the nozzle was $0.8 \mathrm{~mm}$. The working pressure was 380 $\mathrm{MPa}$. The water-jet with the abrasivum affected perpendicularly to the cutting edge of the sample. The distance of the nozzle above the cut material was $3 \mathrm{~mm}$.

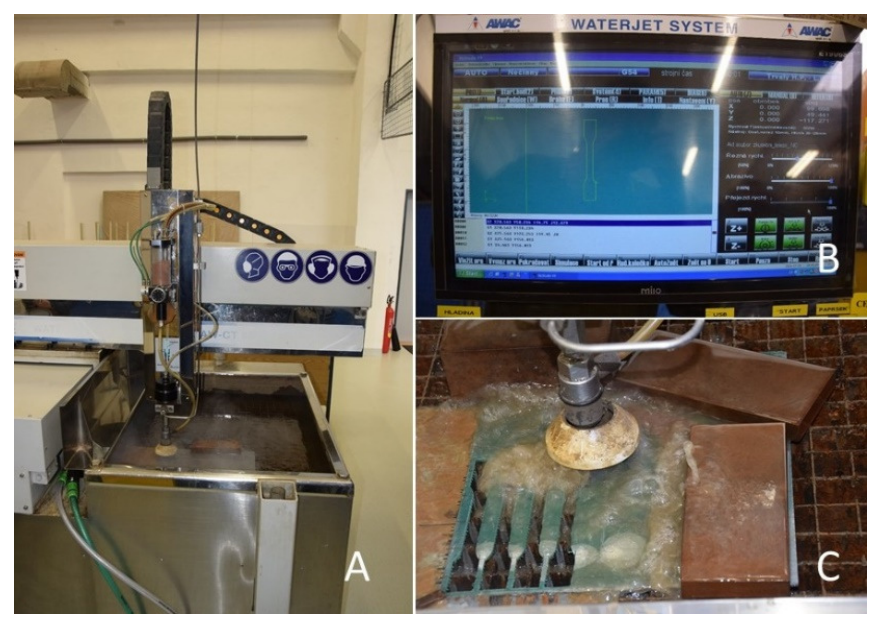

Fig. 1. Machining of polymeric composites by means of water-jet technology: A: CNC AWJ CT 0806, B: Water-jet system, C: Production of test samples, composite board cutting 


\section{Results and discussion}

Penetration of the composite material and the water flow into the crack occur after an impact of the water-jet with the abrasivum to the composite material. A water wedge is created which causes crack spreading. A course of the cut by means of the AWJ technology at the particle composite filled with glass-bead microparticles is shown in Fig. 2. Fig. 2 A shows considerable destruction after the impact of the water-jet with the abrasivum towards a smooth cut in the middle and bottom part of the cut (Fig. 2 B). The glass-bead belongs among fillers with good wettability of the surface. This was also certified by the contemporary research. The glass-bead particles were firmly connected with the matrix and it came to their destruction (owing to brittleness - Fig. 2 B) or to their cut (Fig. 2 C).
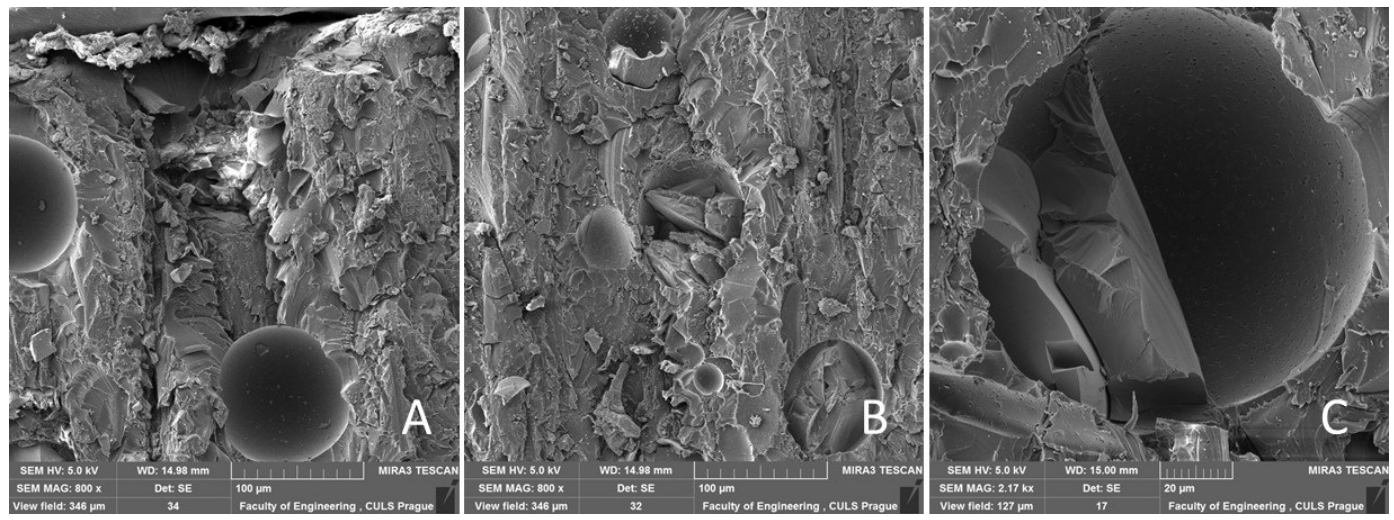

Fig. 2. SEM image - Composite material with glass-bead particle filler: A: Significant deformation of composite after input of water-jet with abrasivum into composite (MAG $800 \mathrm{x}$ ), B: Middle part of cut by water-jet with abrasivum of composite (MAG $800 \mathrm{x}$ ), C: Destruction of filler owing to cutting

(MAG $2.17 \mathrm{kx}$ )

A course of the cut by means of the AWJ technology at the particle composite filled with corundum microparticles is shown in Fig. 3. Fig. 3 A shows a significant destruction after the impact of the water-jet with the abrasivum towards the smooth cut in the middle and bottom part of the cut (Fig. $3 \mathrm{~B}, \mathrm{C}$ ). The particles of corundum were firmly connected with the matrix and it came to their destruction (Fig. 3 B). However, delamination of the filler and the matrix (Fig. 3) occurred more often.
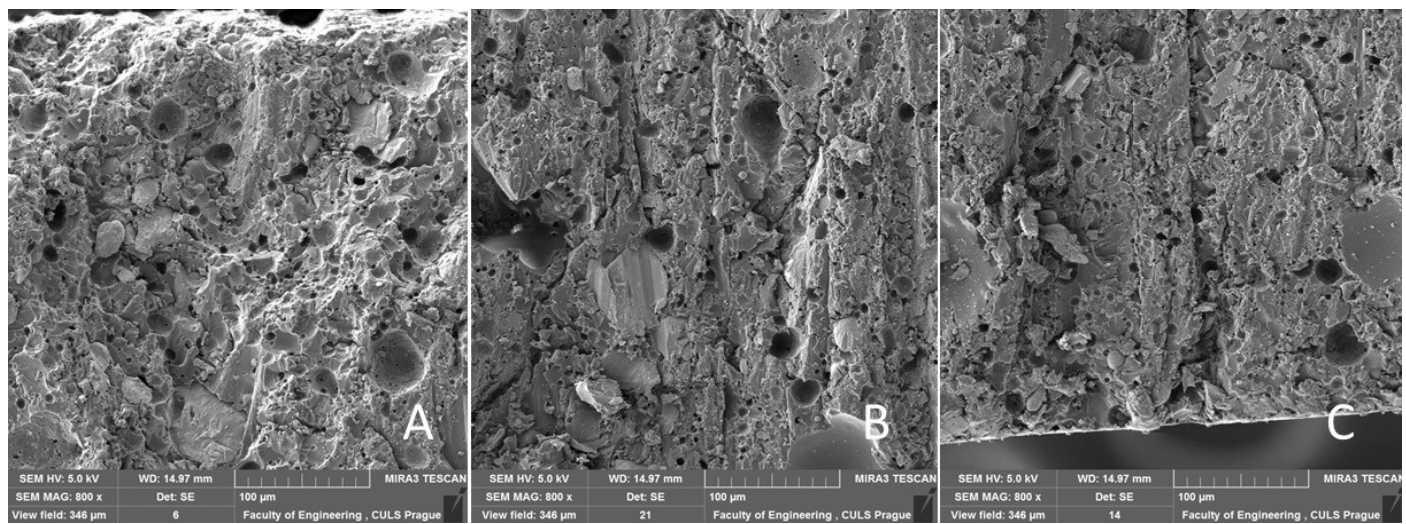

Fig. 3. SEM image - Composite material with filler based on corundum microparticles: A:

Significant deformation of composite after input of water-jet with abrasivum to composite (MAG 800 x), B: Middle part of cut by water-jet with abrasivum of composite (MAG 800 x), C: Final part of cut

by water-jet with abrasivum of composite (MAG $800 \mathrm{x}$ )

A course of the cut by means of the AWJ technology at the composite with the biological filler short fibres of the false banana Ensete Ventricosum is shown in Fig. 4. A significant destruction after the impact of the water-jet is again shown in Fig. 4 A. The middle and final part of the cut was without more significant destruction, the surface was even (Fig. 4 B). The biological reinforcement of the false banana Ensete Ventricosum was cut. It came to its deformation in the direction of the streaming abrasive water-jet (Fig. 4 C). Also pull-up of the fibre in the upper part, i.e. in the place of the beginning of the action of the abrasive water-jet, is shown in Fig. $4 \mathrm{C}$. The behaviour of short fibres of the biological reinforcement from the false banana Ensete Ventricosum at cutting by the AWJ 
technology was of similar trend found by the SEM analysis at the tensile loading and the impact loading $[15 ; 16]$.
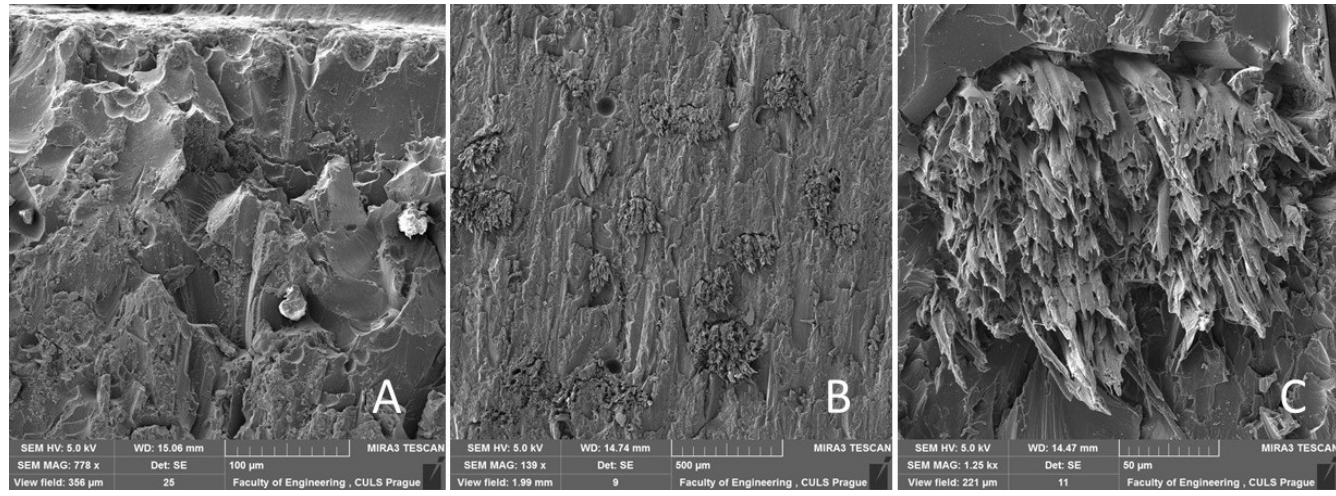

Fig. 4. SEM image - Composite material with biological reinforcement - short fibres of false banana Ensete Ventricosum: A: Significant deformation of composite after input of water-jet with abrasivum into composite (MAG $778 \mathrm{x}$ ), B: Middle area of cut by water-jet with abrasivum of composite (MAG 139 x), C: Destruction of short fibres of biological reinforcement of false banana Ensete Ventricosum owing to cutting (MAG $1.25 \mathrm{kx}$ )

The result of the EDX analysis is detection of single chemical elements and their amount. EDX analysis set the presence of the elements stated in Fig. 5. Data are presented in mass percentage portion. It is obvious from the results that the abrasivum (the garnet) stays in the cut. Although the chemical composition of the garnet is variable, the main admixtures are $\mathrm{Fe}, \mathrm{Mg}, \mathrm{Mn}, \mathrm{Ca}, \mathrm{Al}$ and others. It happens, in some cases, that the abrasive particles carried by the stream of the liquid remain wedged in the crack. This conclusion was certified (Fig. 5) [8].
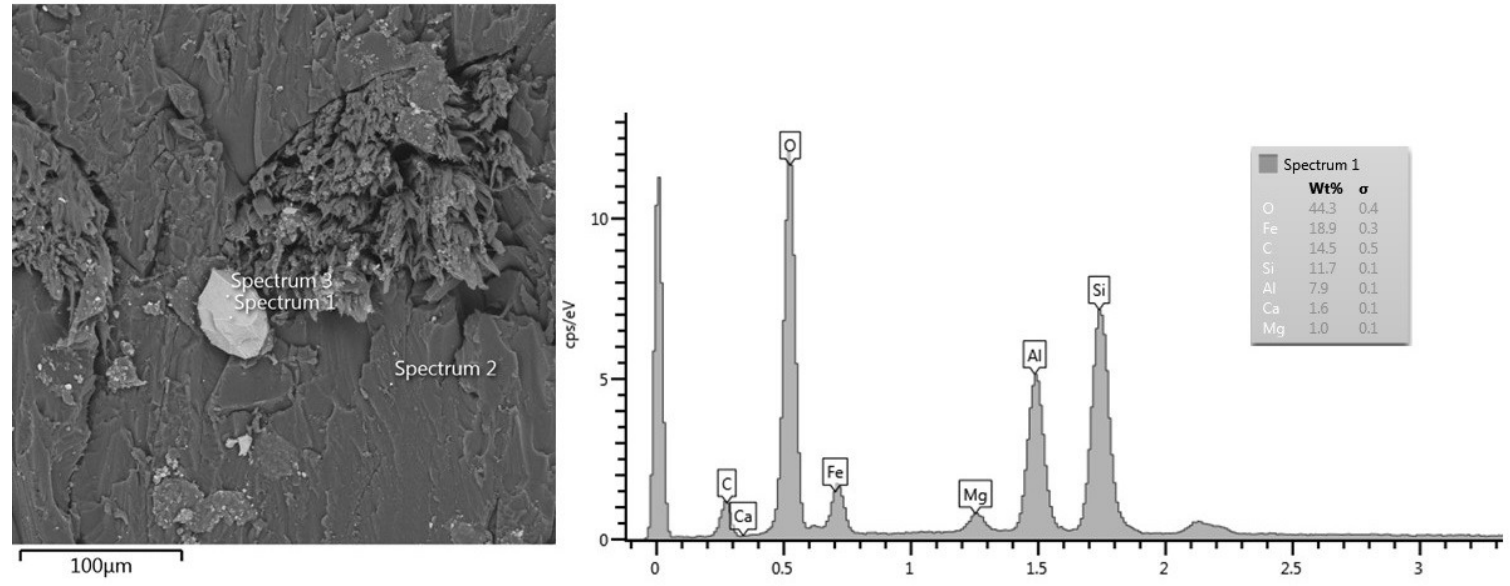

\section{Fig. 5. Results of EDX analysis of cut by AWJ method of composite material with filler in form} of short fibres of false banana Ensete Ventricosum

The course of the cut by means of the AWJ technology at the fibre composite reinforced with glass fabric is shown in Fig. 6. Fig. 6 A shows again a significant destruction of longitudinal and transverse fibres after the impact of the water-jet at the beginning of the cut. The cut of the fibres positioned perpendicularly to the cutting plane is shown in Fig. $6 \mathrm{~B}$. It is apparent from the cuts stated in Fig. $6 \mathrm{~B}$ and $\mathrm{C}$ that it did not come to the upsetting of the composite layer, i.e. the fibres and the matrix. Partial cuts of the reinforcing fabric, i.e. the glass fibres, occurred by the AWJ technology (Fig. 6 C).

The research results proved that the change of the fracture surface orientation occurred at cutting by the AWJ technology under the same impact angle of the abrasive water-jet (Fig. 7 A, B). Azmira et al. dealt with a similar issue [18]. The real effect of the cutting orientation is very much a subject for discussion where it may well depend on the nature of fibres, the mechanics of the fibre fracture and the cohesiveness of the matrix and the reinforcement [18]. Machining of glass fibre reinforced 
polymer composites requires the need for better understanding of cutting processes regarding the accuracy and the efficiency [18].
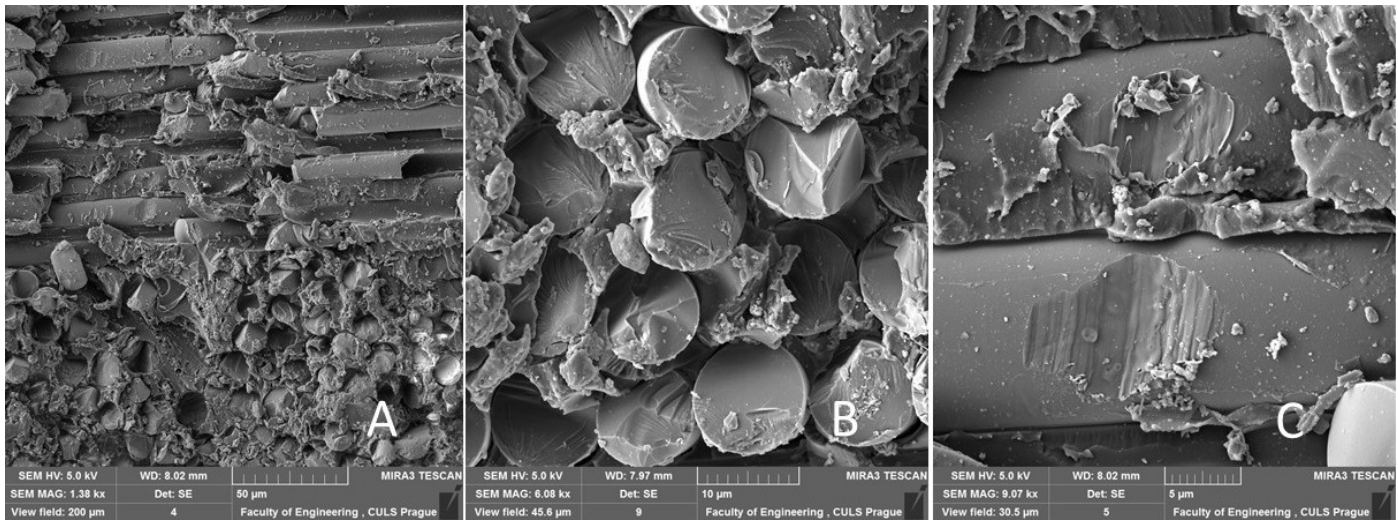

Fig. 6. SEM image - Fibre composite material reinforced with glass fabric: A: Significant destruction of composite fibres (MAG $1.38 \mathrm{kx}$ ), B: Cut of fibres positioned perpendicularly (MAG $6.08 \mathrm{kx}$ ), C: Partial cut of fibres positioned horizontally (MAG 9.07 kx)
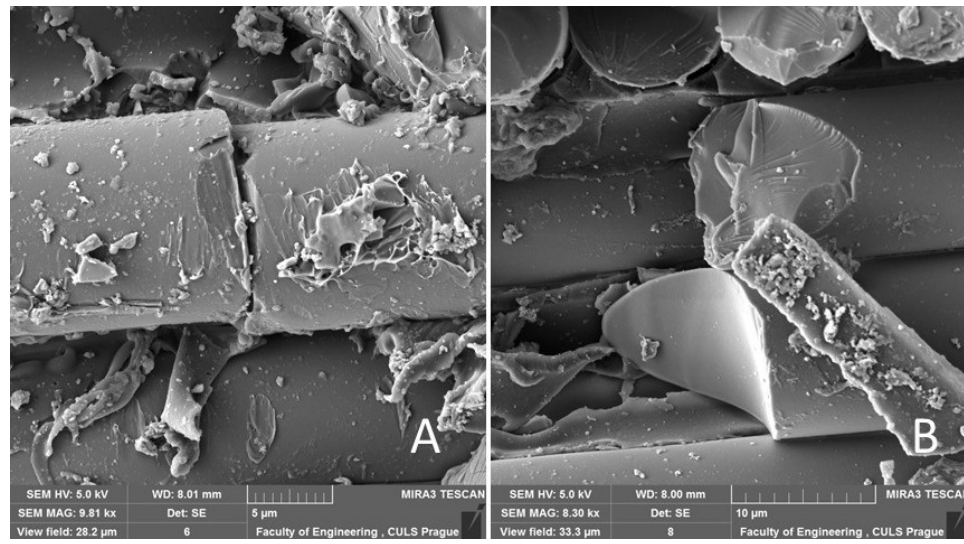

Fig. 7. SEM image - Fibre composite material reinforced with glass fabric: A: Fibre fracture at cutting (MAG $9.81 \mathrm{kx}$ ), B: Fibre fracture at cutting (MAG $8.30 \mathrm{kx}$ )

It was proved that delamination of the composite layer initiates itself at the impact of the shockwave of the abrasive water-jet in the beginning stage, i.e. on the material surface. This conclusion was certified at particle as well as fibre composites (biological, synthetic) [8]. It is possible to agree with the statement that the experiments performed at graphite epoxy composites showed good results at cutting by the water-jet comparing with other tested technologies [9]. However, the results proved delamination of layers at various cutting speeds. The delamination of the layers at fibre composites was proved, namely, at the cut initiation [9]. The analysis done for the surface roughness for both of the best and worst case showed that abrasive water-jet performed much better than plain water-jet [2]. The research proved that quality cuts of polymeric composite materials could be prepared by the AWJ technology [19]. The research on tribological properties, machining etc. of composite materials is important [20]. Particles from the composite material can release at the unsuitable production method and they can make the tribological properties worse [21].

\section{Conclusions}

The research based on the SEM analysis proved that the AWJ technology was a prospective method for cutting polymeric composite materials. There is a problem with initiation of the cut, i.e. penetration of the abrasive jet into the composite layer where it comes to its significant destruction. Delamination and significant removal of the material show themselves in the first stage of cutting. The subsequent cut is regular. Depending on the type of the particle it comes to its delamination. The AWJ technology proved to cut in the effective way also reinforcing glass fabric, corundum and glass-bead particles without their delamination from the matrix. 


\section{Acknowledgement}

Supported by Internal grant agency of Faculty of Engineering, Czech University of Life Sciences in Prague (No. 2017:31140/1312/3115).

\section{References}

1. Kušnerová M., Foldyna J., Sitek L., Valicek J., Hloch S., Harnicarova M., Kadnar M. Innovative approach to advanced modulated waterjet technology. Technicki Vjesnik-Technical Gazette, vol. 19 (3), 2012, pp. 475-480.

2. Kusmierczak S. Methods of evaluation degraded parts. $14^{\text {th }}$ International Scientific conference: Engineering for rural development. May 20-22, 2015, Latvia Univ. Agr., Fac. Eng., Latvia, pp. 790-794.

3. Naprstkova N., Kalincova D. Influence of additional chemical components on machining properties of selected aluminium-silicon alloy. $14^{\text {th }}$ International Scientific conference: Engineering for rural development. May 20-22, 2015, Latvia Univ. Agr., Fac. Eng., Latvia, pp. 799-771.

4. Vesela K., Pexa M., Marik J. Analysis of particle abrasive wear of engine oil when using lasernet fines analyzer. $5^{\text {th }}$ Trends in Agricultural Engineering 2013, September 3-6, 2013, CULS, Czech Republic, pp. 637-641

5. Brožek M. The Turning of Overlays Using Sintered Carbide Tools. International Journal of Advanced Manufacturing Technology. vol. 40(5-6), 2009, pp. 438 - 446.

6. Hloch S., Hlavacek J., Vasilko K., Carach J., Samardzic I., Kozak D., Hlavaty I., Scucka J.J., Klich, Klichava D. Abrasive waterjet (AWJ) titanium tangential turning evaluation. Metalurgija, vol. 53(4), 2014, pp. 537-540.

7. Wang J., Guo D.M. A predictive depth of penetration model for abrasive waterjet cutting of polymer matrix composites. Journal of Materials Processing Technology, vol. 121, 2002, pp. 390-394.

8. Shanmugam D.K., Nguyen T., Wang J. A study of delamination on graphite/epoxy composites in abrasive waterjet machining. Composites: Part A, vol. 39, 2008, pp. 923-929.

9. Shanmugam D.K., Chen F.L., Siores E., Brandt M. Comparative study of jetting machining technologies over laser machining technology for cutting composite materials. Composite Structures, vol. 57, 2002, pp. 289-296.

10. Sleger V., Müller M., Zavrtalek J. Low-cyclic fatigue of adhesive bonds reinforced with fibres. Proceeding of 6th international conference on trends in agricultural engineering 2016, September 7-9, 2016, Prague, Czech Republic, pp. 644-651.

11. Valasek P. Utilization of secondary raw biomaterials in form of microparticles in interaction with reactive resin. $14^{\text {th }}$ International Scientific Conference Engineering For Rural Development 2015, May 20-22, 2015, Latvia Univ. Agr. Fac. Engn., Latvia, pp. 236-241.

12. Valasek P., Chocholous P. Effect of the load on two-body abrasion process of composites based on waste. $5^{\text {th }}$ International conference on Trends in Agricultural Engineering 2013, September 36, 2013, CULS, Czech Republic, pp. 632-636

13. Ruggiero A., Valášek P., Müller M. Exploitation of waste date seeds Phoenix dactylifera in form of polymeric particle biocomposite: Investigation on adhesion, cohesion and wear. Composites Part B-Engineering, vol. 104, 2016, pp. 9-16.

14. Valasek P., Müller M. Impact strength of polymer particle composites with filler on the basis of corundum waste. Engineering for Rural Development, May 24-25, 2012, Jelgava, Latvia, pp. 304308.

15. Müller M., Valasek P., Ruggiero A. Strength characteristics of untreated short-fibre composites from the plant ensete ventricosum. BioResources, vol. 12(1), 2017, pp. 255-269.

16. Mizera C., Herak D., Hrabe P., Muller M. Kabutey A. Mechanical Behavior of Ensete ventricosum Fiber Under Tension Loading. Journal of Natural Fibers, vol. 14(2), 2017, pp. 287-296.

17. Lemma E., Chen F.L., Siores E., Wang J. Study of cutting fiber reinforced composites by using abrasive waterjet with cutting head oscillation. Compos Struct. vol. 57, 2002, pp. 297-303. 
18. Azmira M.A., Ahsan A.K., A study of abrasive water jet machining process on glass/epoxy composite laminate. Journal of Materials Processing Technology, vol. 209, 2009, pp. 6168-6173.

19. Wang J. Abrasive waterjet machining of polymer matrix composites-cutting performance, erosive process and predictive models. Int J Adv Manuf Technol. vol. 15, 1999, pp. 757-768.

20. Ruggiero A., Merola M., Carlone P., Archodoulaki V. M. Tribo-mechanical characterization of reinforced epoxy resin under dry and lubricated contact conditions. Composite Part B: Engineering. vol. 79, 2015, pp. 595-603.

21. Ruggiero A., D’Amato R., Merola M., Valášek P., Müller M. Tribological characterization of vegetal lubricants: Comparative experimental investigation on Jatropha curcas L. oil, Rapeseed Methyl Ester oil, Hydrotreated Rapeseed oil. Tribology International, vol. 109, 2017, pp. 529-540. 